\title{
Air plasma for medical applications
}

\author{
Spencer P. Kuo
}

Department of Electrical \& Computer Engineering, Polytechnic Institute of New York University, Brooklyn, USA

Email:skuo@duke.poly.edu

Received 16 June 2012; revised 13 July 2012; accepted 15 August 2012

\section{ABSTRACT}

The design and the electric and emission characteristics of two handheld air plasma spray generators are presented. The plasma is generated by $60 \mathrm{~Hz}$ periodic discharges between two concentrically cylindrical electrodes. A ring magnet is used to rotate arc discharges, which sprays outward by an air flow. The average electric power of the discharge is about $170 \mathrm{~W}$. The rotation of arc discharges keeps the generated plasma in non-equilibrium state and at relatively low temperature $\left(<55^{\circ} \mathrm{C}\right)$. The plasma effluent yet contains high energy electrons which dissociate molecular oxygen into atomic oxygen. The spatial distribution of $777.4 \mathrm{~nm}$ radiation intensity from the emission spectroscopy of the plasma plume reveals that the plasma effluent carries abundant atomic oxygen which extends out from the cap of the plasma spray by about 25 to 30 $\mathrm{mm}$. Tests on blood droplets and smeared blood samples were performed. It is shown that the degree of blood clotting decreases with the decrease of the RAO flux in the plasma effluent and increases with the increase of the exposure time to the plasma effluent. The results revealed the effectiveness and mechanism of low temperature air plasma on clotting blood. The medical applications of an air plasma spray for 1) bleeding control and for 2) wound healing are then illustrated and discussed. As animal models, pigs were used in the tests of stopping wound bleeding and post-operative observation of wound healing by this air plasma spray. The results show that bleedings of different wounds from a straight cut and a cross cut in the ham area, and a hole in a saphenous vein and a cut to an artery in an ear are all stopped swiftly; this air plasma spray also shortens the wound healing time to about half (from 14 days to 8 days) after applying it for 10 seconds to stop the bleeding of a cross cut wound in the ham area.

Keywords: Plasma Spray; Blood Coagulation; Bleeding Control; Wound Healing; Oral Pathogens and Biofilms; Atomic Oxygen Generation; Emission Spectroscopy

\section{INTRODUCTION}

Air plasma generated in an open environment makes it easy for practical applications; one of the current focuses is plasma medicine. Air plasmas carry chemically active species, such as molecular oxygen in metastable states and atomic oxygen. These reactive species are capable of destroying a broad spectrum of chemical and biological warfare (CBW) agents [1-11] as well as activation of erythrocyte - platelet interactions for blood coagulation [12]. The effectiveness of reactive oxygen species (ROS) (particularly, reactive atomic oxygen (RAO)) in killing the toughest biological agents, bacterial spores, has been demonstrated by Herrmann et al. [2] and Lai et al. [3], respectively. Ambrosio et al. [13] suggested that reactive oxygen metabolites affect thrombus formation within the vasculature. Kalghatgi et al. [14] showed that a non-thermal atmospheric pressure plasma [15], produced by a dielectric barrier discharge (DBD), could indeed clot blood samples via a direct contact. Recently, Chen et al. [16] and Kuo et al. [12] showed that an air plasma torch, carrying significant amount of RAO, could clot anticoagulated whole blood samples in less than 20 seconds, which is much less than 30 minutes for an untreated sample to reach complete coagulation. Hence, air plasma can be "green" decontaminant/disinfectant and bleeding controlling agent.

Bleeding, even from an external hemorrhage, may be life threatening if it is not treated swiftly [17-19]. Most cases occur under emergency situations. The treatment has to repair the cause of bleeding, relieve symptoms, and prevent complications [17-28]. Thus new methods and devices which can effectively stop bleeding to save life of injured person, especially in battlefield situations [29], are of significance.

Blood coagulation involves platelet activation and coagulation cascade. When the platelets meet the break situation in the vessel, molecules touch the platelets that trigger platelets activation, followed by coagulation cascade which is a complicated step-by-step blood clotting process. Several proteins (fibrinogen, tissue factor, calcium, etc.) and molecules, called coagulation factors, play important roles in the coagulation cascade. 
Argon plasma coagulator (APC) is operated in endoscope's surgery for bleeding control [30-32]. This device is a high-frequency mono-polar device used for noncontact thermal coagulation of tissue. Argon gas flows through the endoscope to a probe where the discharge occurs to generate argon plasma, which then converts the RF energy into heat to cauterize and desiccate blood. However, APC is not suitable for the external applications because it has a very small treatment area and the heat treatment causes thermal damage to the nearby tissue of the wound. In plasma coagulation applications for the external wounds, it will be desirable to have low temperature plasmas which open to the ambient and can cover a large area in the treatment.

Plasma generated by stationary arcs has high temperature and small volume. Gas flow can be introduced to increase the plasma volume, such as a DC plasma torch. However, the temperature of the plasma is still too high for the considered applications. On the other hand, by introducing a DC magnetic field to rotate arcs and employing periodic discharges, it has been shown that torches [33-35] can produce low-temperature non-equilibrium air plasmas. The advantage of producing non-equilibrium plasma is better usage of the electron energy, gained from the discharge, for producing reactive oxygen species (ROS) [36], rather than heating the plasma.

In the present work, a plasma torch module is described and its medical applications are illustrated. In Section 2, the design and structure of the module are described; the electric characteristics of the discharge are presented. The $777.4 \mathrm{~nm}$ radiation intensity of the plasma spray is measured and the likely processes of atomic oxygen generation in the plasma effluent are discussed. Tests of plasma treatment on blood droplets and smeared blood samples are conducted. The results are presented in Section 3, in which the plasma coagulation mechanism is discussed. The medical applications of this plasma spray for bleeding control and wound healing are illustrated and discussed in Sections 4 and 5. Summary and discussions are given in Section 6.

\section{DESIGN OF THE DEVICE}

The design of a magnetized arc torch module [34] is described as follows. This module, as shown by the schematic in Figure 1(a), consists of a pair of concentric electrodes, a ring-shaped permanent magnet, a cylindrical frame, and a position holder. The top surface of the outer electrode is a ring shape with an inner diameter of a. The central electrode, a cylindrical copper rod of diameter $\mathrm{d}$, is inserted through the ring magnet and a tight fit position holder which keeps the central electrode along the central axis of the cylindrical frame. This holder has large openings to permit the flow of air generated by a blower to pass through it. The magnet, sitting on a step inside the frame and located slightly below the gap between the electrodes, has an inner diameter $b$ larger than the inner diameter a (i.e., $\mathrm{b}>\mathrm{a}$ ) of the outer electrode to allow the airflow to pass through it and to avoid undesired discharge between the central electrode and the magnet. This ring magnet produces a magnetic field in the electrode gap region, $\mathrm{B}=\mathrm{B}_{\mathrm{z}} \hat{\mathrm{z}}+\mathrm{B}_{\mathrm{r}} \hat{\mathrm{r}}$, which acts on the current density of the discharge, $J=J_{z} \hat{z}+J_{r} \hat{r}$, with a force density $\mathrm{F}=\mathrm{J} \times \mathrm{B}$ in the azimuthal direction. The resulting azimuthal force rotates the discharge, thus avoiding the formation of hot spots on the electrode surfaces. This stabilizes the discharge, slows down the build-up of the arc temperature, and reduces arc erosion on the electrodes.

The air enters the bottom of the tubular frame of the module through a flexible air duct that connects to a blower. A cap is introduced to direct the flow of the plasma effluent as well as to cover the electrodes for safety, so that the high voltage (HV) central electrode is not exposed. The height $\mathrm{h}$ of the cap and the diameter $\mathrm{c}$ of the cap opening are adjustable.

The size of the module varies with the specific application. In the following, we exemplify two, as shown in Figures 1(b) and (c), which are used in the considered applications. In the schematic of Figure 1(a), the central electrode has a diameter $\mathrm{d}=4.7625 / 3.175 \mathrm{~mm}\left(0.1875^{\prime \prime} /\right.$ $0.125^{\prime \prime}$ ) for that in Figures 1(b) and (c), respectively. The inner and outer diameters of the ring-shaped outer copper electrode are $\mathrm{a}=6.73 / 4.7625$ and $25.4 / 15.875$ $\mathrm{mm}\left(0.265^{\prime \prime} / 0.1875^{\prime \prime}\right.$ and $\left.1 " / 0.625^{\prime \prime}\right)$. A ring-shaped magnet of the size of 19 (od) $\times 8.7$ (id) $\times 2$ (h) $\mathrm{mm} / 12$ (od) $\times$ 6 (id) $\times 2$ (h) $\mathrm{mm}$ (i.e., $\mathrm{b}=8.7 / 6 \mathrm{~mm})$ is used. It produces a magnetic field of $\sim 0.18 \mathrm{~T}$ (Tesla) in the electrode gap region. The cap opening has a diameter $\mathrm{c}=12.5 / 9.5 \mathrm{~mm}$ and is positioned about $\mathrm{h}=12.7 / 12 \mathrm{~mm}$ above the outer electrode. The airflow speed at the cap exit of the plasma spray was measured by an Air Velocity Meter (tsi model 1650). The airflow rate was then estimated from integrating the speed distribution over the cross section of the cap. The airflow rate and the average flow speed at the electrode gap (and cap exit) were evaluated to be about $3 / 1.67 \mathrm{\ell} / \mathrm{s}$ and $170 \mathrm{~m} / \mathrm{s}(24.5 \mathrm{~m} / \mathrm{s})$, respectively.

The plasma spray was run in periodic mode with a duty cycle of about $15 / 50 \%$ for the two modules presented in Figures 1(b) and (c), respectively. The time varying voltage $V(t)$ and current $I(t)$ of the discharge were measured using a digital oscilloscope (Tektronix TDS3012 DPO $100 \mathrm{MHz}$ and $1.25 \mathrm{GS} / \mathrm{s}$ ), where $\mathrm{V}$ is the voltage of the central electrode of the module (the outer electrode is grounded). The product of the $\mathrm{V}$ and I functions gives the instantaneous power function $\mathrm{P}(\mathrm{t})$. These three time functions, $\mathrm{V}, \mathrm{I}$, and $\mathrm{P}$, in one cycle, are presented together in Figures 1(d) and (e), for the two modules, to show their phase relationship. In each cycle 

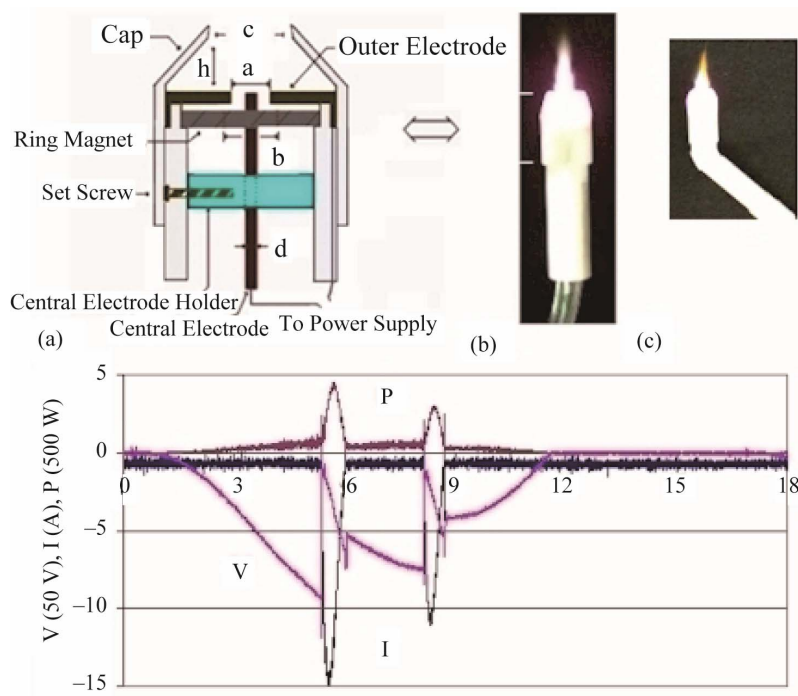

(d)

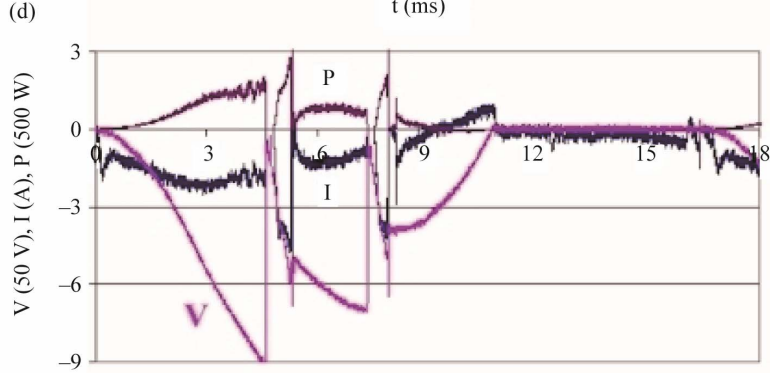

(e) $\mathrm{t}(\mathrm{ms})$

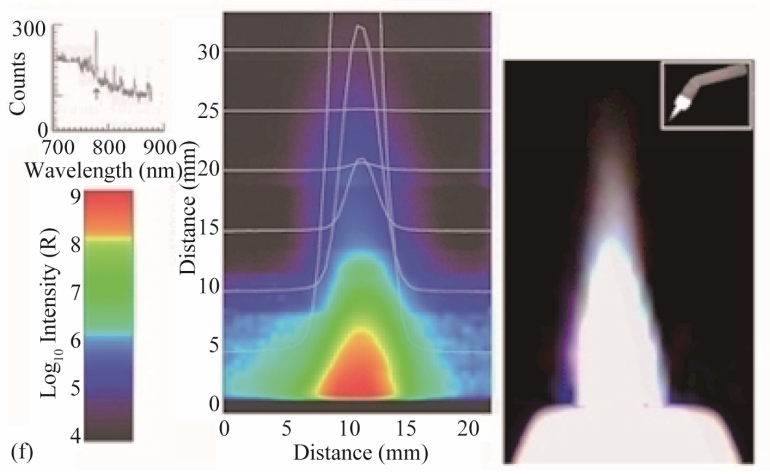

Figure 1. A schematic (a) of a plasma generator module and photos ((b) and (c)) of two different size and shape modules; plots ((d) and (e)) of the voltage $\mathrm{V}(\mathrm{t})$, current $\mathrm{I}(\mathrm{t})$, and power $\mathrm{P}(\mathrm{t})$ of the electric discharges in one cycle from the two modules in (b) and (c), respectively; the spatial distribution (f) of $777.4 \mathrm{~nm}$ radiation intensity of the plasma plume produced by the module shown in (c).

of the $60 \mathrm{~Hz} \mathrm{AC}$ input there is no discharge in the positive half cycle due to a rectifier diode used in the circuit. In the negative half cycle two discharges are arranged. This is done by adding a HV induction coil as a trigger of the discharge in the circuit of the power supply. With the aid of the trigger, the voltage of the power supply is reduced to $500 \mathrm{~V}$. The peak powers in the discharge of the two modules are about $2 / 1.5 \mathrm{~kW}$ and the average powers for both modules are about $170 \mathrm{~W}$. It is noted that the discharge in the smaller one presented in Figure 1(c) is a glow/arc hybrid, which is due to the smaller discharge gap of the module.

The discharges are prevented from arc constriction by the introduced airflow and magnetic field. The airflow increases the path of the arc discharge by pushing it outward to form a loop. The magnetic field rotates the discharge loops to prevent the formation of hot spots on the electrodes. Thus the discharges are maintained stably in the diffused arc loop form and the produced plasma effluent protrudes to the outside of the cap by about 25 to $30 \mathrm{~mm}$.

The average temperature of the plasma effluent outside the cap was measured by a temperature meter "Omega DP460" (Omega Engineering, Inc., Stamford, $\mathrm{CT})$. The response time of the thermocouple of the meter is about 0.5 seconds. We have exposed the probe to the plasma spray to obtain a steady state reading from the meter. The time averaged temperature was determined from the readings. Although the size of the thermocouple was too large to provide a good spatial resolution, the measurement showed that the temperature of the plasma effluent, produced by both modules, outside the cap exit was less than $55^{\circ} \mathrm{C}(328 \mathrm{~K})$. This thermal temperature is much lower than the excitation temperature of electrons channeled by the rotating arc loop, which is estimated via emission spectroscopy to be larger than $7700 \mathrm{~K}$. This plasma spray is non-equilibrium due to the following factors associated with the design and the operation, 1) the discharge is run in a periodic mode with a duty cycle of about $15 / 50 \%$, rather than in a dc mode; 2) discharge occurs outside the electrodes and the gas flow increases the size of the arc loop considerably. Thus, because the discharge extends 10 to $20 \mathrm{~mm}$ beyond the discharge gap, a considerable number of electrons are generated in the region well away from that near the electrodes; 3) the discharge is run in relatively high voltage/relatively low current mode (e.g., relative to the plasma transfer arc torches); and 4) the magnetic field rotates the arc discharge, preventing the formation of arc constriction and hot spots on the electrode surfaces.

The reactive atomic oxygen (RAO) flux of the plasma jet was examined via the emission spectroscopy of the plasma plume $[35,36]$. We measured the spatial distribution of $777.4 \mathrm{~nm}$ radiation intensity (in Rayleighs), for the smaller module (Figure 1(c)), from the 5P state of atomic oxygen (OI), ranging from $<10^{4}$ to $>10^{9}$, as shown in Figure 1(f). The visible plasma plume extends out axially to about $25 \mathrm{~mm}$ from the cap of the plasma spray, where the intensity of $777.4 \mathrm{~nm}$ radiation is about $10^{5} \mathrm{R}$; i.e., the apparent photon emission from a slice of the plasma plume at $25 \mathrm{~mm}$ away from the cap is about $10^{15} \mathrm{~m}^{-2} \cdot \mathrm{sec}^{-1}$. 
There are three likely processes to produce atomic oxygen; one is to dissociate an oxygen molecule into two oxygen atoms via the reaction $\mathrm{e}+\mathrm{O}_{2} \rightarrow 2 \mathrm{O}+\mathrm{e}$, which has a reaction rate coefficient $\mathrm{k}_{1}=4.2 \times 10^{-9} \exp \left(-5.6 / \mathrm{T}_{\mathrm{e}}\right)$ [37], where $T_{e}$ is in eV. This reaction rate decreases rapidly with $\mathrm{T}_{\mathrm{e}}<5.6 \mathrm{eV}$; thus it needs about $5 \mathrm{eV}$ electrons to effectively dissociate $\mathrm{O}_{2}$ into atomic oxygen. The second one is through recombination of charged particles $e+$ $\mathrm{O}^{+} \rightarrow \mathrm{O}$, which may not need the presence of energetic electrons. The third one is the dissociative attachment of electrons to molecular oxygen e $+\mathrm{O}_{2} \rightarrow \mathrm{O}+\mathrm{O}^{-}$; conservation of energy requires that the electron energy exceeds a threshold level, which normally is $3.6 \mathrm{eV}$. Though this threshold level decreases as the internal energy of molecular oxygen increases, laboratory experimental results [38] show that this level can go down to 1 $\mathrm{eV}$ and less. Therefore, the third process of dissociative attachment is likely the dominant process of atomic oxygen generation in this low temperature plasma spray. The 5P state of the transition in atomic oxygen OI has rather high energy, about $10.74 \mathrm{eV}$, relative to the ground state, therefore, the strong line intensity outside the core of the plasma plume indicates that plasma is in a non-equilibrium state with a strong presence of high-energy electrons $(\geq 1 \mathrm{eV})$ and an abundant concentration of $5 \mathrm{P}$ state atomic oxygen in the plasma effluent, as calculation assuming low optical thickness represents a minimum bound on the average density. Since OI in other states (in particular, in the ground state) may also be produced, the total OI concentration in the plasma effluent may be much higher than that of 5P state alone.

\section{IN-VITRO TESTS ON BLOOD COAGULATION}

Blood is a fluid tissue that includes $60 \%$ of a liquid portion known as blood plasma, and $40 \%$ of formed elements or blood cells [39]. Blood plasma is the liquid portion of the blood - a protein-salt solution which suspends red blood cells (RBC), white blood cells (WBC), and platelets alike. Formed elements consist $86.6 \%$ of RBC, $10.4 \%$ of platelets, and $3 \%$ of WBC. WBC consists of neutrophils, eosinophils, basophils, monocytes, and lymphocytes [39].

Formed elements and blood plasma contribute to blood coagulation during hemorrhage. Blood plasma contains albumin (the chief protein constituent), fibrinogen (responsible, in part for blood clotting), globulins (including antibodies) and other clotting proteins [39]. RBC contains hemoglobin, a complex iron-containing protein that carries oxygen and participates in carbon dioxide exchange. Platelets play a vital role in the early response to vascular injury and blood clot formation as they adhere to injured vessel wall components, become activated, agglomerate and secrete mediators that promote platelet activation and attract WBC [40-42]. The average lifetime for WBC is hours to days, for RBC 120 days, and for platelets 9 days. Platelets are more fragile cells and 3 - 4 times smaller than $\operatorname{RBC}[39,43,44]$.

In order to prevent premature blood coagulation, obtained blood was mixed with a $3.2 \%$ sodium citrate solution on a 9:1 ratio (in volume). The sodium citrate solution is a commonly used reagent to prevent blood from clotting by chelating calcium ions $[45,46]$.

\subsection{Tests on Blood Droplets}

Two tests to separate the effects of heat and plasma effluent (oxygen radicals) on blood clotting were performed first. Test 1 was performed with a blood droplet set on a glass slide, placed at $25 \mathrm{~mm}$ below the nozzle of the spray exposed directly to the plasma effluent. Direct exposure treatment continued for a period of $12 \mathrm{sec}$. The sample temperature rose to $52^{\circ} \mathrm{C}$. The result of the test is presented in Figure 2(a). A shell, formed on the blood sample surface, can be clearly seen. In the second test, a blood droplet was set in a well and treated for $16 \mathrm{sec}$ by a hot airflow of a hair dryer, which raised the sample temperature to about $61^{\circ} \mathrm{C}$. A photo of the sample taken after this hot air treatment is presented in Figure 2(b) for a comparison. No noticeable blood clotting can be identified. This comparison clearly shows that the blood coagulation appearing in Figure 2(a) cannot be attributable to the thermal effect of hot air.

We next examined the dependence of coagulation on the reactive oxygen species flux (mainly RAO indicated by the emission spectroscopy) in the plasma effluent by fixing the exposure times to $16 \mathrm{sec}$. The tests were conducted at three exposure distances, namely 25,30 , and $40 \mathrm{~mm}$. The exposure times of $16 \mathrm{sec}$ in each test were, in fact, accumulations of 4-sec exposures, with a 2-second pause after two consecutive 4-second exposures. The sample temperatures rose to about $50^{\circ} \mathrm{C}$ in all three tests. Although all treated samples, presented in Figure 3, manifested blood clotting, as evidenced by shell formation on the blood sample surfaces, the degree of blood clotting differs as the dissimilar blood sample surface structure led to conclude. As the degree of dryness and hardness of a shell increases, the bubble on that shell surface tends to collapse and consequently form dimples. As seen in Figure 3(c), the shell is smoother than the other two shown in Figures 3(a) and (b). Furthermore, the bubble of the shell in Figure 3(a) appears collapsed. Results show that the degree of blood clotting decreases with increasing exposure distance. This tendency is consistent with the decrease of the RAO flux in the plasma effluent with increasing exposure distance. Three treated samples, with exposure times of 8,12 , and $16 \mathrm{sec}$, are presented in Figures 4(a) to (c) to demonstrate that the degree of blood clotting increases with exposure time, 

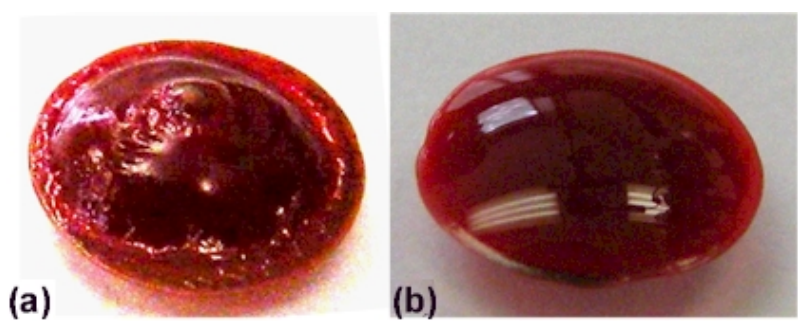

Figure 2. Blood samples treated by (a) the plasma spray and (b) a heated airflow.

(a)

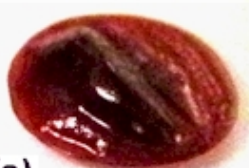

(b)
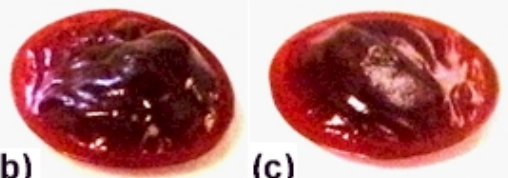

(c)

3. Samples treated with a total of 16-sec exposure time (4-sec exposures, with a 2 -sec pause between two consecutive exposures) at three exposure distances, namely (a) $25 \mathrm{~mm}$; (b) $30 \mathrm{~mm}$; and (c) $40 \mathrm{~mm}$.
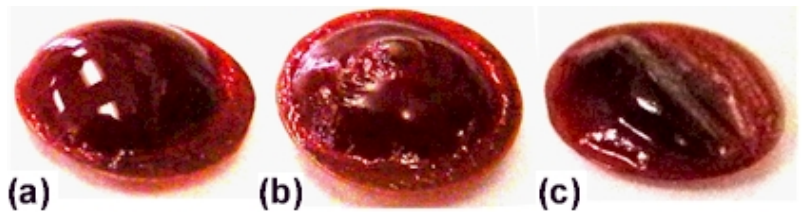

(b)

(c)

Figure 4. Samples treated at three exposure times (a) $8 \mathrm{sec}$, (b) $12 \mathrm{sec}$, and (c) $16 \mathrm{sec}$, at a fixed exposure distance of $25 \mathrm{~mm}$.

with a constant exposure distance of $25 \mathrm{~mm}$.

It is understood that the pain of the wound is sensitive to the heat; thus, an intermittent approach was tried. It applies several short exposures to achieve clotting. It is found that this approach could in fact be more effective in clotting blood. The required total exposure time depends on the period of each short exposure as well as the pause time between two consecutive exposures. This observation is illustrated by comparing six treated samples presented in Figures 5(b)-(g); an untreated sample is presented in Figure 5(a) for a reference. The samples were treated at the same exposure distance of $25 \mathrm{~mm}$ and with the same total exposure time of $8 \mathrm{sec}$. However, the treatment procedures were different. In Figures 5(b)-(d), the treatments were $2 \mathrm{sec}$ exposure 4 times with pause times of 1,2, and $4 \mathrm{sec}$. The degrees of clot are estimated to be $10 \%-15 \%, 20 \%-25 \%, 45 \%-50 \%$, respectively. The treatments in Figures 5(e) and (f) were 4 sec exposure twice with 2 and $4 \mathrm{sec}$ pause times; the degrees of clot are estimated to be $20 \%-25 \%$ and $30 \%-40 \%$, respectively. In Figure 5(g), the sample was continuously exposed to the plasma effluent for $8 \mathrm{sec}$. The degree of clot was only $5 \%-10 \%$ even though the temperature of this sample was raised to about $50^{\circ} \mathrm{C}$, the highest among all samples presented in this figure. (b)

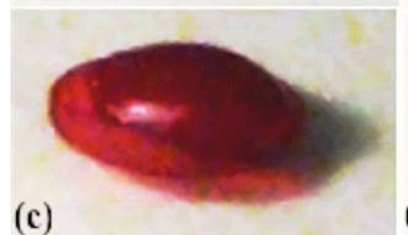

(e)

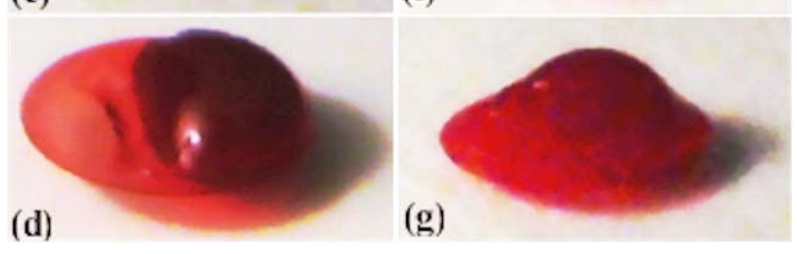

Figure 5. (a) Untreated blood sample, and (b)-(g) samples treated with 8 -sec exposure at $25 \mathrm{~mm}$ exposure distance; (b)-(d) 2 -sec treatment 4 times with 1-, 2-, and 4-sec pause; (e) and (f) 4-sec treatment twice with 2- and 4-sec pause; (g) 8-sec treatment once.

Among the reactive oxygen species produced by atomic oxygen, hydrogen peroxide $\left(\mathrm{H}_{2} \mathrm{O}_{2}\right)$, a non-radical yet oxidant species plays a special role in platelet coagulation. High concentration of $\mathrm{H}_{2} \mathrm{O}_{2}$ inhibits platelets aggregation [47-49] while low concentration of $\mathrm{H}_{2} \mathrm{O}_{2}$ promotes thromboxane synthesis, and hence platelet aggregation. This concentration-dependent activity may explain the experimental results in Figure 5 showing that plasma-assisted blood coagulation is more effective with accumulated treatment time (lower concentration as $\mathrm{H}_{2} \mathrm{O}_{2}$ was consumed during the pauses between plasma treatments) than that with a continuous treatment time (higher concentration as $\mathrm{H}_{2} \mathrm{O}_{2}$ was produced continuously).

\subsection{Tests on Smeared Blood Samples}

Untreated (control) and plasma spray-treated smeared blood samples were prepared for cell staining and microscopy analysis. Cell types were identified by cell staining and microscopy and cell count were performed. Percentages of RBC, WBC, and platelets in the total cell count of each sample were evaluated. We did not find any deviating values for WBC. On the other hand, cell counts revealed that in the sample treated with longer exposure time and shorter exposure distance, the percentage of 
RBC increased, while the percentage of the platelets decreased. These two dependencies on exposure distance and time are shown in Figures 6(a) and (b), respectively.

This was confirmed by identification of cell types using cell staining and cell counts. The significant reducetion of the percentage of platelets of the treated sample evidenced the impact of the plasma effluent on platelets; in particular, because RBC concentration should not change much, it is suggested that, in fact, the platelet count of the treated sample was reduced.

\subsection{Coagulation Mechanism}

As shown in Figure 3, blood clotting decreases with the increase of exposure distance. Likewise, as shown in Figure 1(f), RAO carried by the plasma effluent of the torch also decreases with increasing exposure distance. The experimentally observed dependencies can be summarized as follows. The platelet count of a treated sample is less than that of the control (Figure 6(a)) and decreases with the increase of both RAO flux and blood clotting (Figure 3), which is done by decreasing the exposure distance. With an increase in the exposure time, platelet count of treated samples decreases (Figure 6(b)), while blood clotting increases (Figure 4). These correlations lead us to propose a blood clotting mechanism as shown in Figure 7.

The cartoon plots in Figure 7 are used to explain the plasma torch coagulation mechanism. Presumably, RAO in the plasma effluent creates oxidants, such as $\mathrm{H}_{2} \mathrm{O}_{2}$ and $\mathrm{OH}$, in the blood. These oxidants contribute to $\mathrm{RBC}-$ platelets and WBC interactions (Figure 7(a)), which in return causes a noticeable decrease in blood flowability.

These interactions influence the concentration of cells suspended in blood (Figure 7(b)). The increase of RBC can be observed under the microscope. Consequently, coagulation is on the rise, while platelets are decreasing. This is due to trapping within globular complexes (Fig-

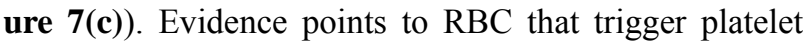
adherence/agglomeration in vitro, as well as blood clotting [50-53]. It was shown that platelet agglomeration was associated with the loss of adenine nucleotides released by RBC [54], the extent of which increased together with RBC [55]. In addition to blood clotting, which transiently stops bleeding, platelets provide a surface for the subsequent steps of the coagulation leading to clot formation $[41,42]$. Additionally, platelets are fragmented by oxidants to induce coagulation and subsequent blood clot formation (Figure 7). Viscosity of blood samples will also be affected by oxidants that presumebly contribute to the denaturation of albumin [56] as well as other proteins found in the blood. Taken together, our results demonstrate that air plasma induces coagulation with the involvement of RBC, platelets (Figure 7), and most likely albumin. Prospective studies on RBC only or platelets only and/or platelets/albumin enriched/depleted samples will confirm our current findings.

NO can lead to anti-inflammation and anti-thrombotic effects which inhibit platelet adhesion, increases blood flowability, and lowers blood pressure [57]. NO containing drugs such as an NO donor (e.g., nitroglycerin) or NO inhalant, demonstrated to inhibit platelet agglomeration [57-64]. NO suppresses platelet agglomeration in vitro and in vivo via the guanylyl cyclase mechanism [59-64]. Furthermore, exposure to the inhaled NO significantly decreases platelet agglomeration in rats [61] and in humans accompanied by acute respiratory distress syndrome $[57,58]$. The present air plasma spray operates at a relatively low temperature $\left(<55^{\circ} \mathrm{C}\right.$ outside the nozzle). The NO flux in the plasma effluent outside the nozzle is relatively low and does not significantly quench the



(a)

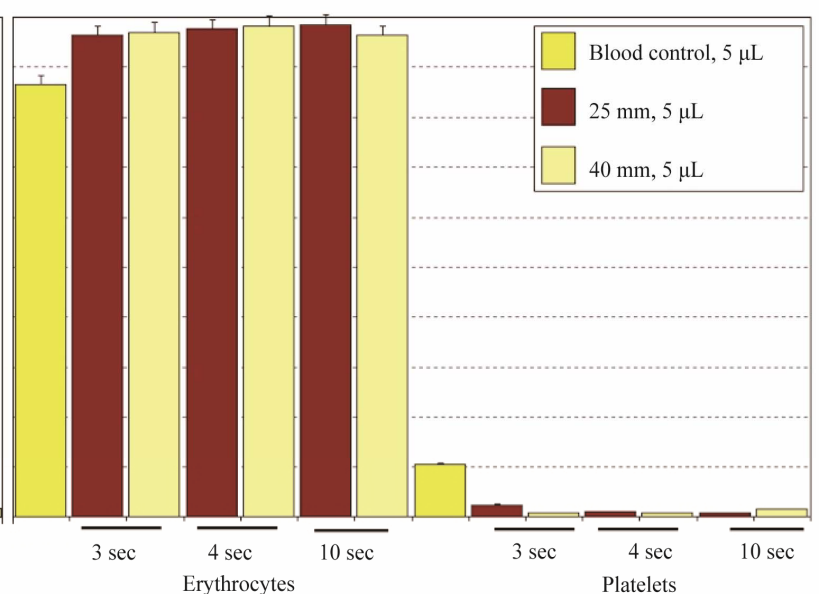

(b)

Figure 6. Dependencies of the blood composition of untreated/plasma-treated samples on (a) the exposure distance, with a fixed exposure time of $10 \mathrm{sec}$, and on (b) the exposure time, in the two cases of 25 and $40 \mathrm{~mm}$ exposure distances. 


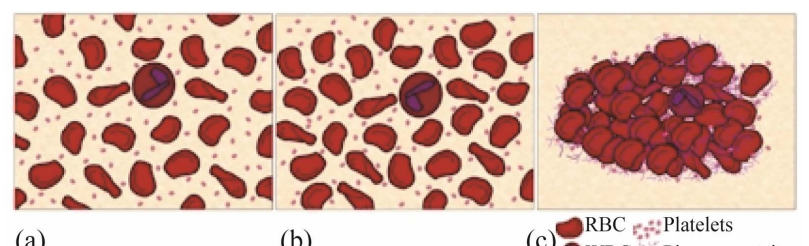

(a)

(b)

(c) ${ }_{\mathrm{WBC}}^{\mathrm{RBC}}$ Platelets

Figure 7. Cartoon plots showing the clotting process induced by the plasma torch.

effect of RAO involved in platelet agglomeration and inducing blood coagulation.

It is noted that other reactive oxygen species (ROS), such as $\mathrm{O}_{3}$, in addition to RAO, can also create oxidants in the blood to induce coagulation via the proposed mechanism. In the scan of the spectrometer, the UV radiation from $300 \mathrm{~nm}$ to $400 \mathrm{~nm}$ was not detected. Moreover, intensive lines contributed by oxygen radicals appeared only around $777.4 \mathrm{~nm}$; this could be because the emissions of molecule species were distributed in the bands with much lower spectral intensities. Given the limitations of spectroscopic diagnostics, we could not rule out the existence of other ROS in the plasma spray, which were also partially responsible for the observed coagulation.

\section{BLEEDING CONTROL}

Experiments were conducted to demonstrate the effectiveness of the air plasma spray on stopping bleeding from a straight cut, a cross cut, a hole onto an ear saphenous vein, and a cut to an ear artery.

Two 3-month-old male pigs weighing around $25 \mathrm{~kg}$ were used in the first three experiments [65]; the wound introduced on one pig was treated by the plasma; the other pig was an untreated control whose wound was stopped by itself. Three 6 mouth-old male pigs weighing around $40 \mathrm{~kg}$ were used in the last experiment [66]. The left ears of the pigs were the control group and the right ears were the experimental group. The bleeding time of a similar wound on the untreated control was recorded to be the natural clotting (bleeding) time for a comparison with that of the corresponding treated wound.

Each pig was first injected with calmative-Stresnil and fastened on a table. The pig was then anesthetized with Isoflurance-Fluothane which kept it in a narcotized state. Tests were conducted in the sequence of a straight cut first, and then a cross cut, and a hole in an ear saphenous vein, and finally a cut to an ear artery, in the order of increasing difficulty of bleeding control. Enough time between the tests was given for pigs to recover from the bleeding.

After the experiments, pigs were put into stainless experiment cages for postoperative observation of recovery. The stainless cage prevents pig to scratch an itchy part of the wounds against the wall during the recovery period.

\subsection{Test 1-Straight Cut}

A scalpel was used to make a straight cut to each pig in the similar ham area. The size of each cut was about $1 \mathrm{~cm}$ in length and $0.5 \mathrm{~cm}$ in depth. One cut was not treated. Presented in Figure 8(a) is a photo of this untreated cut taken at $190 \mathrm{~s}$ later as the bleeding stopped naturally. This time is defined as the total bleeding time. The straight cut on the second pig was treated by the plasma at an exposure distance of $2.5 \mathrm{~cm}$. The bleeding stopped completely after $18 \mathrm{~s}$ of continuous plasma treatment, as demonstrated in Figure 8(b). The treated cut appears to be covered only by small amount coagulated blood. This is because in the treatment, the airflow from the spray blew away the remaining blood which did not clot in time. Two similar tests with the exposure distance increased to 3 and $4 \mathrm{~cm}$ were also performed. The coagulation times in two cases were measured to be 17 and $21 \mathrm{~s}$, respectively.

\subsection{Test 2-Cross Cut}

We next performed a cross cut, which consisted of two straight cuts cross to each other, to each pig in the similar ham area. Again, the size of each cut was about $1 \mathrm{~cm}$ in length and $0.5 \mathrm{~cm}$ in depth and the exposure distance was $2.5 \mathrm{~cm}$. The bleeding from the untreated cross cut lasted for more than 4 minutes. A photo of the cut taken after

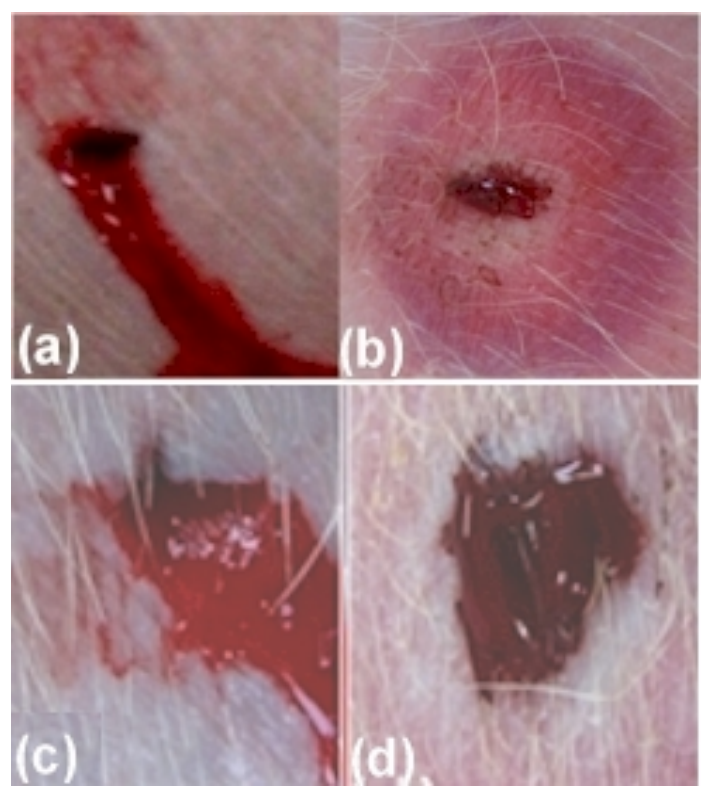

Figure 8. Photos of straight cuts ( $a$ and $b$ ) and cross cuts ( $c$ and d) taken (a) after more than 2 minutes waiting time for bleeding to stop naturally, (b) after bleeding stopped by a plasma treatment of $18 \mathrm{~s}$, (c) after 4 minutes waiting time for bleeding to stop naturally, and (d) after the bleeding stopped by $13 \mathrm{~s}$ plasma treatment. 
the bleeding stopped naturally is presented in Figure 8(c). On the other hand, the bleeding from the cut on the other pig was treated by the plasma spray continuously. It was stopped after $13 \mathrm{~s}$ treatment. A photo of this cross cut coagulated with the aid of the plasma treatment is presented in Figure 8(d). The needed treatments in the other two exposure distances of 3 and $4 \mathrm{~cm}$ were measured to be 17 and $22 \mathrm{~s}$.

\subsection{Test 3-Hole in a Saphenous Vein}

A saphenous vein from a pig ear was first identified as shown in Figure 9(a); next, a needle and forceps were used to punch a hole in this vein as shown in Figure 9 (b). When blood flow started, it was treated immediately by the plasma spray shown in Figure 9(c) with an exposure distance of $2.5 \mathrm{~cm}$. The bleeding stopped in $15 \mathrm{~s}$ as demonstrated in Figure 9(d). In the untreated control, the bleeding time of the other pig was measured to be about $88 \mathrm{~s}$. A considerably more bleeding can be seen in Figure 9(e).

\subsection{Test 4-A Cut to an Artery}

Before cutting an artery, the ear was tied with a tourniquet to slow down the blood flow. A scalpel was then
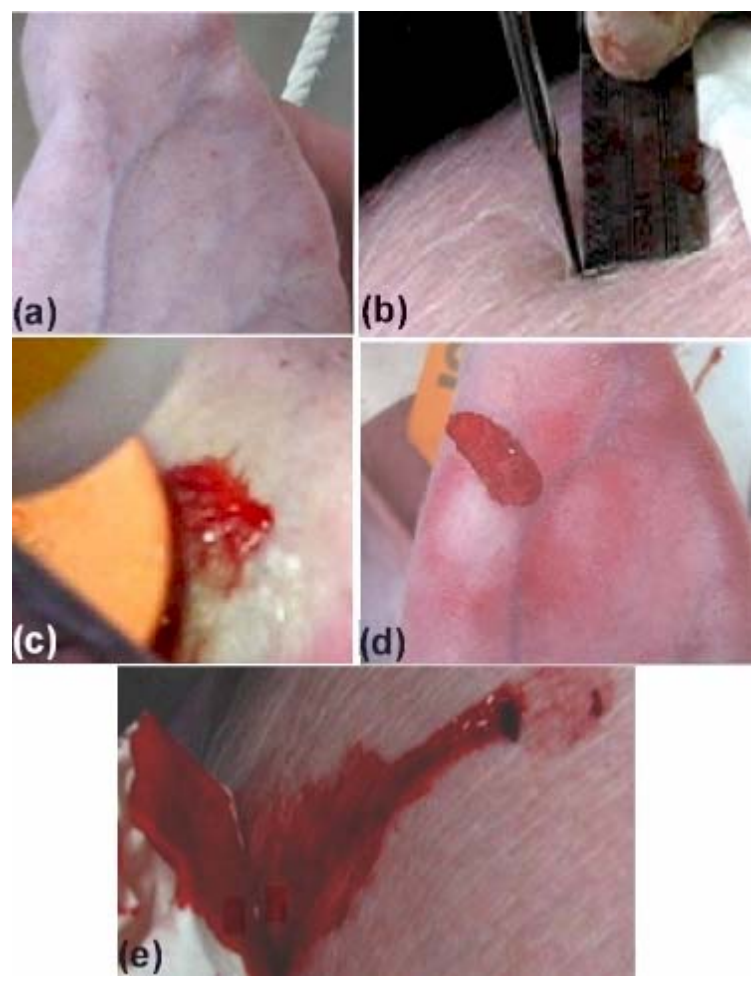

Figure 9. (a) Photo showing a saphenous vein in an ear of a pig, in which (b) a hole is to be punched, (c) air plasma spray is applied, and (d) photo of the punched saphenous vein after $15 \mathrm{~s}$ plasma treatment to block the hole from bleeding. used to cut the ear small artery as shown in Figure 10(a). The needed plasma treatment time and the natural coagulation time were measured for a comparison. In the untreated case, leaving the bleeding unattended as shown in Figure 10(b), it took 1 minute to stop the bleeding naturally. In the plasma treatment as shown in Figure 10(c), an intermittent approach, with plasma 2-s on/4-s off alternately, was adopted. Bleeding was stopped after6 runs of plasma on-off treatment as shown in Figure 10(d). The total treatment time was about $35 \mathrm{~s}$, about half of the natural clotting time; however, the total plasma exposure time was only $12 \mathrm{~s}$. The plasma treatment also irritated the exposure area around the wound, which is circled in Figure 10(d). The healing of the cut and the circled red area is discussed and illustrated in Section 5.2.

Adopting an intermittent plasma treatment is to minimize the thermal factor in the overall plasma effect on wound bleeding control as discussed in Section 3.1. However, in the practical applications, a continuous treatment should be adopted, in particular, in the emergency situation, to further reduce the bleeding time.

\subsection{A Plausible Mechanism}

The experimental results have shown that this plasma spray could rapidly clot blood to stop bleeding. The atomic oxygen produced in the plasma effluent is likely the catalyst in the coagulation processes. When interacted with $\mathrm{H}_{2} \mathrm{O}$, atomic oxygen carried by the plasma
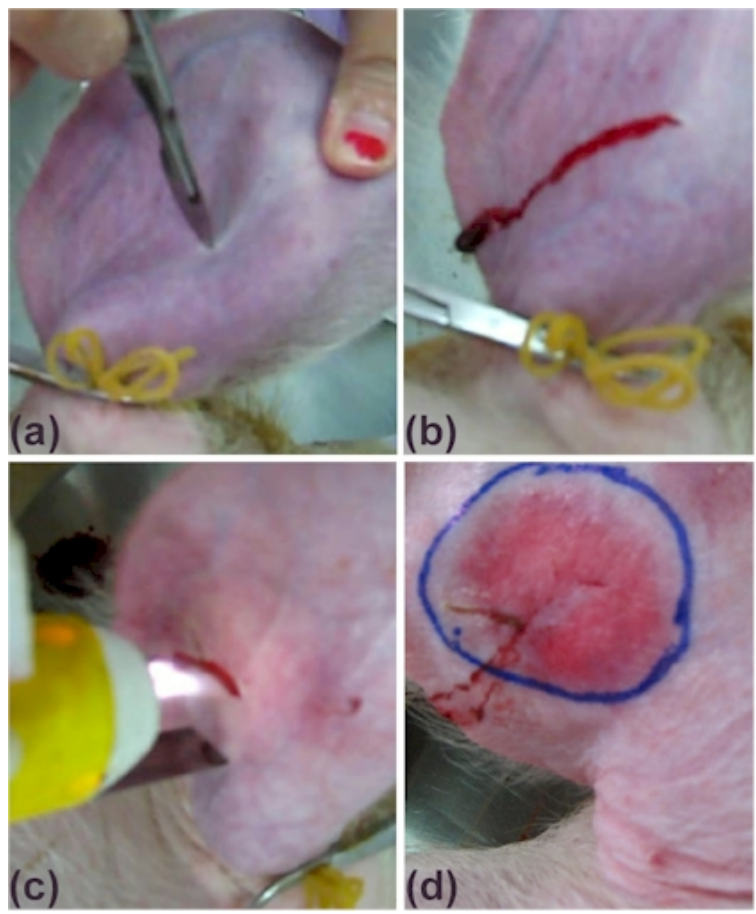

Figure 10. Photos showing (a) cutting an artery and (b) leaving the bleeding to stop naturally; and (c) with plasma treatment and (d) stop the bleeding in half time. 
effluent can generate large amount of reactive oxygen species (oxygen ions, free radicals, and peroxides). Studies have shown that platelets are a prime target for oxidants produced or released in the vascular lumen and, at the same time, they are also capable of endogenous generation of oxidants $[67,68]$. It has also been shown that oxidants can affect several key steps of platelet function to enhance platelet aggregation [68-70].

\section{WOUND HEALING}

In Mammalian skin, the outermost layer is epidermis which has protection formation and waterproof property; the inner layer Dermis provides a location for the appendages of skin [71]. The hair follicles sweat glands, sebaceous glands, lymphatic vessels, blood vessels etc. are contained inside the dermis. The definition of a wound is a break in the epithelial integrity of the skin. The disruption could be deeper, extending to the dermis, muscle or even the bone. The entire wound healing process is a complex and dynamic process of restoring cellular structures and tissue layers in which the damaged skin is being repaired [72]. The physiologic process of wound healing goes through four sequential overlapping phases, which are homeostasis, inflammatory, proliferating and remodeling [73]. The wound healing time varies with the location, age, degree of wound, etc.

After wound is bleeding, the vasoconstriction is taken place and platelets (thrombocytes) aggregate at the wound location to reach homeostasis by forming a fibrin clot. The alpha granules of the platelets contain growth factors, and those proteins start the wound healing cascade by attracting and activating fibroblasts, endothelial cells and macrophages. The platelets trapped in the clot are essential for homeostasis as well as for a normal inflammatory response.

In the inflammatory phase of healing, Polymorph nucleus arrives to the wound site about one hour after injury and become the predominant cells. These phagocytes release enzymes, free radicals, and reactive oxygen species to kill bacteria and other foreign particles. Factors are also released to cause the migration and division of cells involved in the proliferating phase, which is characterized by the replacement of the provisional fibrin matrix with newly formed granulation tissue. This rudimentary tissue contains new blood vessels, fibroblasts, endothelial cells, etc.

The remodeling phase starts concurrently with the development of granulation tissue. In the remodeling phase, collagen matrix is remodeled and collapsed along tension lines and cells. The vessel cells and muscle tissues grow toward the steady state under the collagen matrix. Collagen degrades to scar which is then removed because of apoptosis [74].

It explains why wound healing takes time. The im- pacts of the plasma treatment on the exposure area and on the healing time of the wound are examined in the following experiment.

\subsection{Post-Operative Observation of Wound Healing after Plasma Treatment}

The post-operative observation helps to understand the plasma effluent effect upon the skin tissue surrounding the treated wound and upon the progress of wound recovery. After the experiments pigs were raised in stainless experiment cages to keep them from rubbing their wounds. We then observed the recovering situation by recording the changes of the treated wounds every two days in 14 days.

The progress of the recovery of the artery cut and its surrounding in the circled area of Figure 10(d) can be seen in a sequence of 6 photos, taken every other day at day 2 to day 12 after the plasma treatment, presented in Figures 11(a)-(f). The scab appears at cut first (Figure 11(a)) and then the surrounding irritated area turns to dark brown color (Figure 11(b)); the scab starts peeling in the 8th day (Figure 11(d)) but the dark color in the irritated area starts diminishing in the 6th day (Figure 11(c)). The dark color disappears completely in the 10th day (Figure 11(e)) and a complete healing of the cut is observed in the 12th day (Figure 11(f)). There is no apparent side effect on the irritated area can be seen.

\subsection{Plasma induced Irritation}

To show that there was no scab formed in the area irritated by the plasma exposure and no blemish left on the skin, a ring shape irritation was introduced in a woundfree ham area, by continuous plasma exposure at a distance of $2.5 \mathrm{~cm}$ for $10 \mathrm{~s}$, for the observation. The photo records taken from day 0 to day 14 are presented in Figure 12. As shown, in the healing process, the red ring
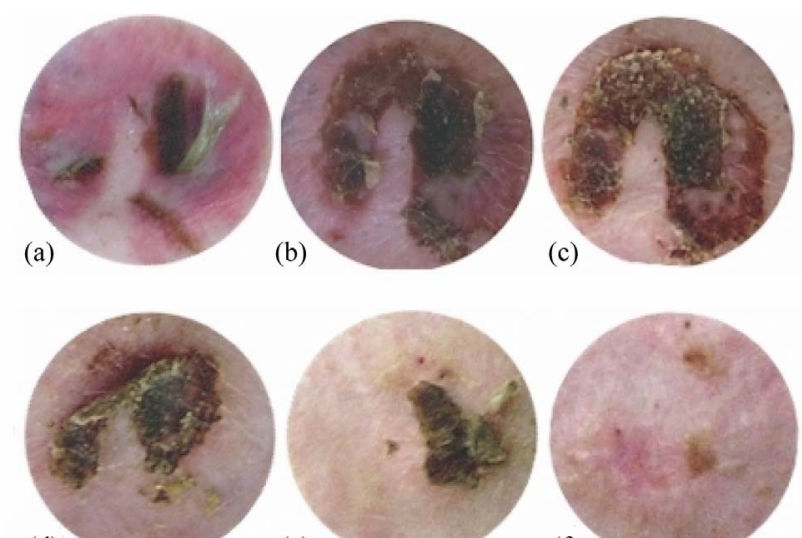

(e)

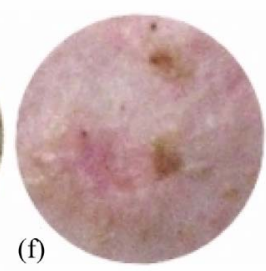

Figure 11. Recovery of an artery cut and its surrounding irritated area after the plasma treatment. 


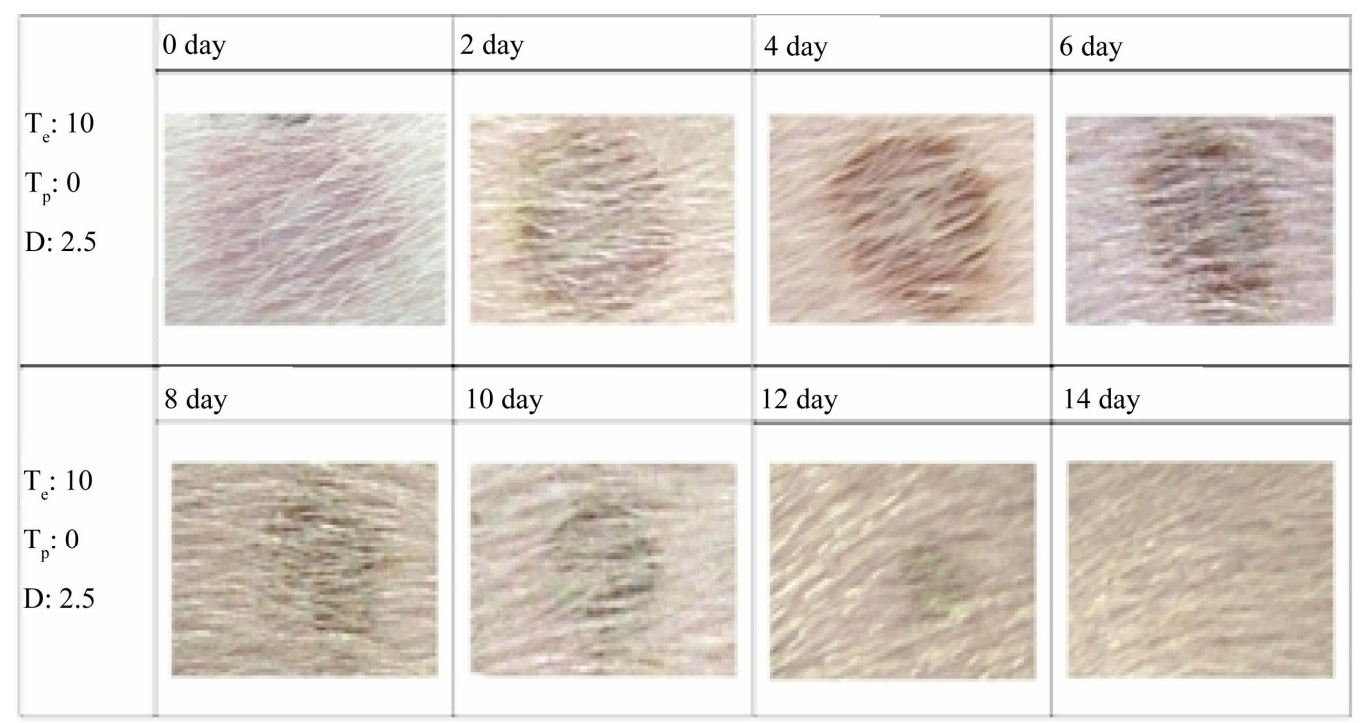

Figure 12. Recovery of an irritated area by the plasma exposure.

turns to dark brown ring; the color becomes darker while the dark brown area is diminishing. It is disappeared completely in the 14th day. In the entire healing process, there is no scab is formed.

Using an intermittent exposure approach with the running parameters $\left(T_{E}, T_{P}, N, D\right)=(2,4,5,2.5)$ to reduce the thermal effect, where $T_{E}, T_{P}, N$, and $D$ represent the plasma-on time at each run, plasma-off (pause) time between two runs, number of runs in a treatment, and exposure distance, respectively, the ring shape irritation could also be induced. The progress of the recovery of the induced irritation is shown in Figure 13. The irritation remained pink in two days and then changed to translucent brown in a smaller area; it was also disappeared completely in the 14th observation day. The temperature of intermittent treatment was lower than that of the continuous treatment, but the brown mark lasted longer. The comparison suggests that the brown tissue is induced by the plasma effluent, probably through ROS on $\mathrm{RBC}$, rather than the thermal effect.

A heat burn wound made by heated iron circle for 4 sec was used as a control. A post-operative observation of this control is presented in Figure 14. Comparing with those presented in Figures 12 and 13, the progress of thermal damage recovery is clear different. Clots, scab, and scar were seen in Figure 14 but not seen in Figures 12 and 13. In Figures 12 and 13, the translucent brown tissue was formed after the disappearance of the pink irritation and looks like aging tissue. The free radical theory of aging (FRTA) introduced by Denham Harman in the 1950s [75] points out that cells are aging via accumulating free radical and oxidative damage over time. The ROS is a main provider to the effective weakens that is characteristic of aging. In order to maintain the normal function, skin tissue is metabolized when tissue is aging. In this test, the treated place accumulates sufficient ROS so this area aging faster than surrounding tissue. The skin tissue increases the metabolism to generate new tissue. The new skin tissue grows up under the ageing tissue, and replaces the position after aging tissue is peeled.

\subsection{Healing of a Cross Cut Wound}

Cross cut wounds were introduced in the ham area of three pigs which were 6-month-old and had a weight of about $40 \mathrm{~kg}$; one was untreated as a control and the other two were treated by the plasma spray with two different intermittent exposure approaches, which applied two different sets of running parameters $\left(\mathrm{T}_{\mathrm{E}}, \mathrm{T}_{\mathrm{P}}, \mathrm{N}, \mathrm{D}\right)=(2,4$, $4,3)$ and $(2,2,5,3)$ for a comparison of the outcomes.

The respective photo recording the healing progresses of the control and two treated cuts are presented in three rows in Figure 15 for a comparison. The progress of the control (untreated cross cut) presented in row 1 indicates that the scab starts peeling in the 8th day. The scab is diminishing in time; however, a small piece of the crust still remains in the wound area in the 14th observation day.

The cut in row 2 was treated with 8 s plasma exposure; it is found that the healing time is shortened. The scab starts peeling in the 6th day, and the crust disappears completely in the 10th day. As the plasma exposure time is increased to $10 \mathrm{~s}$, the healing progress of the cut in row 3 becomes even faster; the starting peeling time of the scab is reduced to 4 days. Moreover, it is shortened to 8 days when the crust disappears completely.

The comparison demonstrates that the plasma effluent has a positive impact on wound healing; it shortens cross cut wound healing time to about half. 


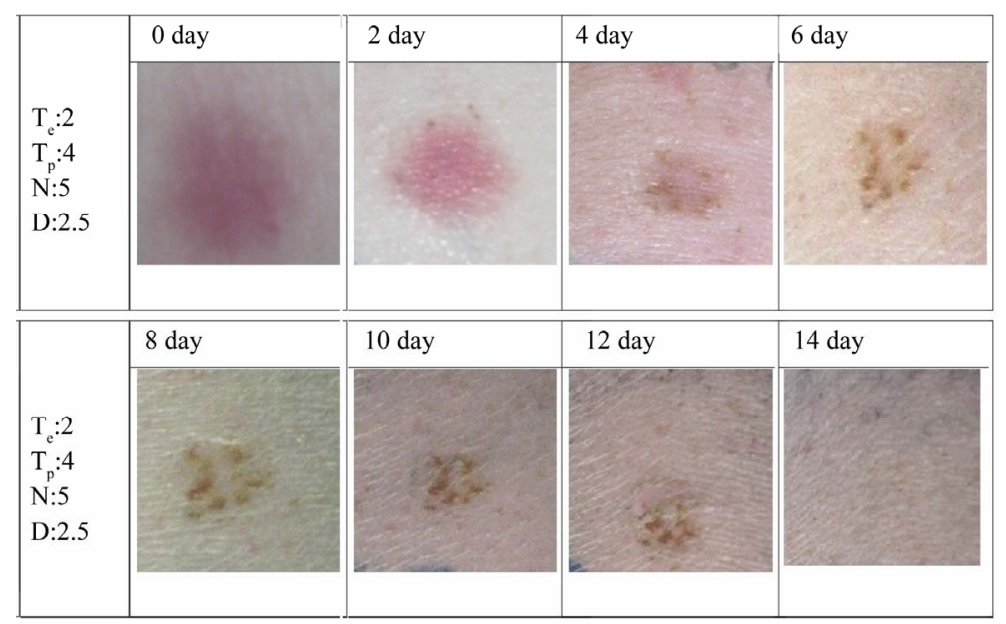

Figure 13. Recovery of an irritated area by an intermittent plasma exposure with $2 \mathrm{~s}$ on/4 s off for 5 times.

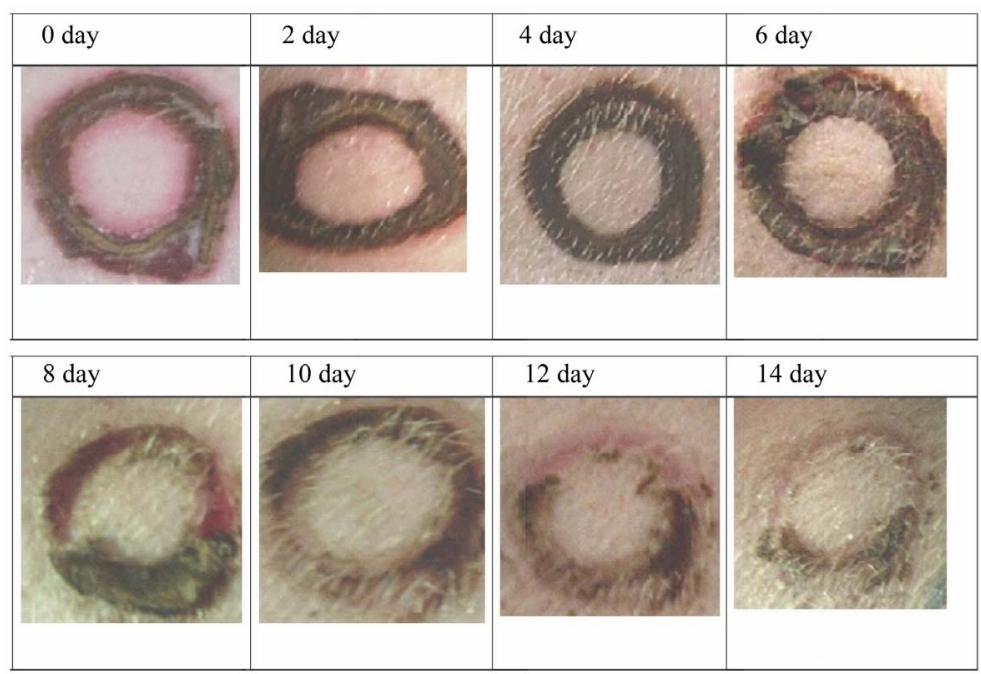

Figure 14. Recovery of an irritated area by an intermittent plasma exposure with $2 \mathrm{~s}$ on/4 s off for 5 times.

\begin{tabular}{|c|c|c|c|c|c|c|c|}
\hline $\begin{array}{c}\text { Cross } \\
\text { cut }\end{array}$ & 2 day & 4 day & 6 day & 8 day & 10 day & 12 day & 14 day \\
\hline \multicolumn{8}{|c|}{$\begin{array}{l}\text { natural } \\
\text { healing }\end{array}$} \\
\hline \multicolumn{8}{|l|}{$\mathrm{T}_{\mathrm{e}}=2$} \\
\hline \multicolumn{8}{|l|}{$\mathrm{T}_{\mathrm{p}}=4$} \\
\hline \multicolumn{8}{|l|}{$\mathrm{D}=3$} \\
\hline \multicolumn{8}{|l|}{$\mathrm{T}_{\mathrm{e}}=2$} \\
\hline $\mathrm{T}_{\mathrm{p}}=2$ & & & & & & & \\
\hline $\begin{array}{l}N=5 \\
D=3\end{array}$ & & & & & & & \\
\hline
\end{tabular}

Figure 15. Comparison of the progress of the recovery of untreated (row 1) and treated (rows 2 and 3 ) cross cuts. 


\subsection{A Plausible Mechanism}

Molecular oxygen is important in metabolism for living organisms and plays a vital role in the healing wound. The oxygen is consumed in all biological reactions and metabolisms for wound healing process [76-78]. Hypoxia [79] acts a key factor to stimulus tissue repair by creating an oxygen gradient from the hypoxic tissue of wound to the nearby unbroken tissue [80]. The central area of the wound is most hypoxic, and the oxygen gradient increase toward the uninjured tissue progressively. However, with the supply of RAO from the plasma spray, the amount of oxygen, consumed to generate $\mathrm{H}_{2} \mathrm{O}_{2}$, is reduced. Consequently, more oxygen can be shared in other action such as producing superoxide (SOD), cell metabolism and raising tissue oxygen tension in the wound healing. RAO also provides the oxygen in the blood by reaction of catalase which plays a protection role avoiding cells damaged by $\mathrm{H}_{2} \mathrm{O}_{2}$. In summary, RAO reduces the demand of oxygen using in respiratory burst and increases oxygen content of tissue indirectly. Both of reducing requirement and increasing supplement paths raise the tissue oxygen tension in the wound site during the plasma treatment, as well as provide the oxygen for wound healing and cell metabolisms.

\section{SUMMARY}

A portable air plasma spray is designed and tested for medical applications. The plasma produced by the discharge is in the non-equilibrium state; i.e., the electron temperature is much higher than that of the neutral gas and ions, which are in thermal equilibrium. This low temperature plasma spray (gas temperature is less than $50^{\circ} \mathrm{C}$ ) produces abundant atomic oxygen in its plasma effluent as indicated by the intense $777.4 \mathrm{~nm}$ radiation.

The intensity distribution of $5 \mathrm{P}$ state OI, plotted in Figure 1, shows that OI in the plasma effluent can extend from the cap of the spray for about $25 \mathrm{~mm}$, which is a relatively large exposure distance for many practical applications. The concentration of $\mathrm{O}_{3}$ in the plasma effluent was not measured.

Atomic oxygen is a strong reactive oxygen species and can effectively kill all kinds of microbes. The present device provides a dry approach for sterilization.

In-vitro tests first verified that the plasma blood clotting was not caused by the thermal effect. The tests also established the strong dependence of the blood clotting on the RAO flux in the plasma effluent. The observed fast decrease of the platelet count coincided with the rapid blood clotting by the plasma effluent suggests that platelets were fragmented by oxidants produced by the RAO flux to induce blood clotting and provide a surface for the subsequent steps of the coagulation leading to clot formation.
In-vivo tests demonstrate that the plasma effluent of the spray can rapidly stop external wound bleeding. The healing time of plasma treated wound is shortened considerably. The understanding is that when interacted with $\mathrm{H}_{2} \mathrm{O}$, atomic oxygen produced by the plasma spray can produce large amount of reactive oxygen species such as $\mathrm{OH}$ and $\mathrm{H}_{2} \mathrm{O}_{2}$. Studies have shown that platelets are a prime target for oxidants produced or released in the vascular lumen and, at the same time, they are also capable of endogenous generation of oxidants. It has also been shown that oxidants can affect several key steps of platelet function to enhance platelet aggregation, leading to blood clotting.

Post-operative observation of wound healing after plasma treatment indicates that the plasma effluent has a positive impact on wound healing and there is no apparent side effect on the irritated skin; it shortens cross cut wound healing time to about half. It is likely that the RAO in the plasma effluent reduces the demand of oxygen using in respiratory burst and increases oxygen content of tissue indirectly; it raises the tissue oxygen tension in the wound site during the plasma treatment and thus increases the oxygen supply from the neighboring tissue for wound healing and cell metabolisms.

\section{ACKNOWLEDGEMENTS}

The author is grateful to Drs. Olga Tarasenko, Cheng-Yen Chen, and Todd Pedersen for collaborative works and to Alessandro Betti for fabricating the air plasma sprays. This work was supported in part by a NYU-Poly seed Grant and in part by the Adventix Technologies Inc.

\section{REFERENCES}

[1] Laroussi, M. (1996) Sterilization of contaminated matter with an atmosphere pressure plasma. IEEE Transactions on Plasma Science, 24, 1188-1191. doi: $10.1109 / 27.533129$

[2] Herrmann, H.W., Henins, I., Park, J. and Selwyn, G.S. (1999) Decontamination of chemical and biological warfare (CBW) agents using an atmospheric pressure plasma jet (APPJ). Physics of Plasmas, 6, 2284-2289. doi: $10.1063 / 1.873480$

[3] Lai, W., Lai, H., Kuo, S. P., Tarasenko, O. and Levon, K. (2005) Decontamination of biological warfare agents by a microwave plasma torch. Physics of Plasmas, 12, 023501023506. doi:10.1063/1.1843131

[4] Baxter, H.C., Campbell, G.A., Whittaker, A.G., Aitken, A., Simpson, A.H., Casey, M., Jones, A.C., Bountiff, L., Gibbard, L. and Baxter, R.L. (2005) Elimination of TSE infectivity and decontamination of surgical instruments using RF gas-plasma treatment. Journal of General Virology, 86, 2393-2399. doi:10.1099/vir.0.81016-0

[5] Tarasenko, O., Nourkbash, S., Kuo, S.P., Bakhtina, A., Alusta, P., Kudasheva, D., Cowman, M. and Levon, K. (2006) Scanning electron and atomic force microscopy to 
study plasma torch effects on $B$. cereus spores. IEEE Transactions on Plasma Science, 34, 1281-1289. doi:10.1109/TPS.2006.878378

[6] Kuo, S.P., Tarasenko, O., Nourkbash, S., Bakhtina, A. and Levon, K. (2006) Plasma effects on bacterial spores in a wet environment. New Journal of Physics, $\mathbf{8}, 41$.

[7] Kalghatgi, S.U., Fridman, G., Cooper, M., Nagaraj, G., Peddinghaus, M., Balasubramanian, M., Vasilets, V.N., Gutsol, A.F., Fridman, A. and Friedman, G. (2007) Mechanism of blood coagulation by nonthermal atmospheric pressure dielectric barrier discharge plasma. IEEE Transactions on Plasma Science, 35, 1559-1566. doi:10.1109/TPS.2007.905953

[8] Kuo, S.P., Tarasenko, O., Popovic, S. and Levon, K. (2006) Killing of bacterial spores contained in a paper envelope by a microwave plasma torch. IEEE Transactions on Plasma Science, 34, 1275-1280.

[9] Kuo, S.P. (2006) Portable arc-seeded microwave plasma torch. US Patent No. 7091441 B1.

[10] Kuo, S.P., Popovic, S., Tarasenko, O., Rubinraut, M. and Raskovic, M. (2007) Fan-shaped microwave plasma for mail decontamination. Plasma Sources Science \& Technology, 16, 581-586.

[11] Kuo, S.P. (2007) Mail decontaminator. China Patent No. I 288005.

[12] Kuo, S., Tarasenko, O., Chang, J., Popovic, S., Chen, C., Fan, H., Scott, A., Lahiani, M., Alusta, P., Drake, J. and Nikolic, M. (2009) Contribution of a portable air plasma torch to rapid blood coagulation as a method of preventing bleeding. New Journal of Physics, 11, 115016.

[13] Ambrosio, G., Oriente, A., Napoli, C., Palumbo, G., Chiariello, P., Marone, G., Condorelli, M., Chiariello, M. and Triggiani, M. (1994) Oxygen radicals inhibit human plasma acetylhydrolase, the enzyme that catabolizes platelet-activating factor. Journal of Clinical Investigation, 93, 2408-2416. doi:10.1172/JCI117248

[14] Kalghatgi, S.U., Fridman, G., Cooper, M., Nagaraj, G., Peddinghaus, M., Balasubramanian, M., Vasilets, V.N., Gutsol, A.F., Fridman, A. and Friedman, G. (2007) Mechanism of blood coagulation by nonthermal atmospheric pressure dielectric barrier discharge plasma. IEEE Transactions on Plasma Science, 35, 1559-1566. doi:10.1109/TPS.2007.905953

[15] Fridman, G., Peddinghaus, M., Ayan, H., Fridman, A., Balasubramanian, M., Gutsol, A., Brooks, A.D. and Friedman, G. (2006) Blood coagulation and living tissue sterilization by floating electrode dielectric barrier discharge in air. Plasma Chemistry and Plasma Processing, 26, 425-442. doi:10.1007/s11090-006-9024-4

[16] Chen, C.Y., Fan, H.W., Kuo, S.P., Chang, J., Pedersen, T., Mills, T. and Huang, C.C. (2009) Blood clotting by low temperature air plasma. IEEE Transactions on Plasma Science, 37, 993-999. doi:10.1109/TPS.2009.2016344

[17] Jevon, P. and Cooper, L. (2005) First aid. Part 5. First-aid treatment for severe bleeding. Nursing Times, 104, 26-27.

[18] Spinella, P.C., Perkins, J.G., McLaughlin, D.F., Niles, S.E., Grathwohl, K.W., Beekley, A.C., Salinas, J., Mehta, S., Wade, C.E. and Holcomb, J.B. (2008) The effect of recombinant activated factor VII on mortality in combat-related casualties with severe trauma and massive transfusion. Journal of Trauma, 64, 286-294. doi:10.1097/TA.0b013e318162759f

[19] Kramer, A.H., Gurka, M.J., Nathan, B., Dumont, A.S., Kassell, N.F. and Bleck, T.P. (2008) Complications associated with anemia and blood transfusion in patients with aneurysmal subarachnoid hemorrhage. Critical Care Medicine, 36, 2070-2075.

doi:10.1097/CCM.0b013e31817c1095

[20] Perkins, J.G., Cap, A.P., Weiss, B.M., Reid, T.J. and Bolan, C.D. (2008) Massive transfusion and nonsurgical hemostatic agents. Critical Care Medicine, 36, S325-S339. doi:10.1097/CCM.0b013e31817e2ec5

[21] Scharf, R.E. (2008) Acquired platelet function disorders: pathogenesis, classification, frequency, diagnosis, clinical management. Hamostaseologie, 28, 299-311.

[22] Trouillas, P. and von Kummer, R. (2006) Classification and athogenesis of cerebral hemorrhages after thrombolysis in ischemic stroke. Stroke, 37, 556-561. doi:10.1161/01.STR.0000196942.84707.71

[23] Franchini, M. (2008) Surgical prophylaxis in von Willebrand's disease: A difficult balance to manage. Blood Transfusion, 6, S33-S38.

[24] Al-Sallami, H., Ferguson, R., Wilkins, G., Gray, A. and Medlicott, N.J. (2008) Bleeding events in patients receiving enoxaparin for the management of non-ST-elevation acute coronary syndrome (NSTEACS) at Dunedin Public Hospital, New Zealand. New Zealand Medical Journal, 121, 87-95.

[25] Roy, P., Bonello, L., Torguson, R., de Labriolle, A., Lemesle, G., Slottow, T., Steinberg, D., Kaneshige, K., Xue, Z., Satler, L., Kent, K., Suddath, W., Pichard, A., Lindsay, J. and Waksman, R. (2008) Impact of "nuisance" bleeding on clopidogrel compliance in patients undergoing intracoronary drug-eluting stent implantation. American Journal of Cardiology, 102, 1614-1617. doi:10.1016/j.amjcard.2008.07.063

[26] Milovanov, A.P. and Kirsanov, Ia.N. (2008) The pathogenesis of uterine hemorrhages in the so-called placental polyps. Arkhiv Patologii Journal, 70, 34-37.

[27] Jamal, M.M., Samarasena, J.B. and Hashemzadeh, M. (2008) Decreasing in-hospital mortality for oesophageal variceal hemorrhage in the USA. European Journal of Gastroenterology \& Hepatology, 20, 947-955. doi:10.1097/MEG.0b013e32830280c7

[28] Thanvi, B.R., Treadwell, S. and Robinson, T. (2008) Haemorrhagic transformation in acute ischaemic stroke following thrombolysis therapy: Classification, pathogenesis and risk factors. Postgraduate Medical Journal, 84, 361367. doi:10.1136/pgmj.2007.067058

[29] USA Today (2009) Advanced first aid for troops sought. 14 September 2009, A1.

[30] Vargo, J.J. (2004) Clinical applications of the argon plasma coagulator. Gastrointest. Endosc., 59, 81-88.

[31] Raiser, J. and Zenker, M. (2006) Argon plasma coagulation for open surgical and endoscopic applications: State of the art. Journal of Physics D: Applied Physics, 39, 
3520-3523.

[32] Malick, K.J. (2006) Clinical applications of argon plasma coagulation in endoscopy. Gastroenterology Nursing, 29, 386-391.

[33] Kuo, S.P. (2012) Plasma assisted oxygen decontaminant generator and sprayer. US Patent No. 8115135.

[34] Kuo, S.P. (2010) Portable Plasma Sterilizer. US Patent No. 7777151.

[35] Kuo, S.P., Pedersen, T. and Mills, T. (2008) Lateral distribution of atomic oxygen flux produced by an array of three fan-shaped plasma torches. IEEE Transactions on Plasma Science, 36, 1056-1057. doi:10.1109/TPS.2004.924556

[36] Kuo, S.P., Pedersen, T. and Mills, T. (2011) Two-dimensional distribution of atomic oxygen multiplet radiation Produced by an air plasma torch. IEEE Transactions on Plasma Science, 39, 2282-2283. doi:10.1109/TPS.2011.2155089

[37] Georg, A., Engemann, J. and Brockhaus, A. (2002) Investigation of a pulsed oxygen microwave plasma by timeresolved two-photon allowed laser-induced fluorescence. Journal of Physics D, 35, 875-881. doi:10.1088/0022-3727/35/9/307

[38] Henderson, W.R., Fite, W.L. and Brackmann, R.T. (1969) Dissociative attachment of electrons to hot oxygen. Physical Review, 183, 157-166. doi:10.1103/PhysRev.183.157

[39] Anthea, M., et al. (1993) Human biology and health. Prentice Hall, Englewood Cliffs.

[40] Reimers, R.C., Sutera, S.P. and Joist, H.J. (1984) Potentiation by red blood cells of shear-induced platelet aggregation: Relative importance of chemical and physical mechanisms. Blood, 64, 1200-1206.

[41] Sachs, U.J. and Nieswandt, B. (2007) In vivo thrombus formation in murine models. Circulation Research, 100, 979-991. doi:10.1161/01.RES.0000261936.85776.5f

[42] Kolev, K., Longstaff, C. and Machovich, R. (2005) Fibrinolysis at the fluid-solid interface of thrombi. Current Medicinal Chemistry-Cardiovascular \& Hematological Agents, 3, 341-355. doi:10.2174/156801605774322337

[43] Bethesda, L.D. (2005) Blood Groups and Red Cell Antigens. National Library of Medicine (US): NCBI.

[44] www.genomesize.com/cellsize/mammals.htm

[45] Greer, J.P., et al. (2003) Wintrobe's clinical hematology. 11th Edition, Lippincott Williams \& Wilkins, Philadelphia.

[46] Fridman, G., Shereshevsky, A., Jost, M., Brooks, A., Fridman, A., Gutsol, A., Vasilets, V. and Friedman, G. (2007) Floating electrode dielectric barrier discharge plasma in air promoting apoptotic behavior in melanoma skin cancer cell lines. Plasma Chemistry \& Plasma Processing, 27, 163-176. doi:10.1007/s11090-007-9048-4

[47] Canoso, R.T., Rodvien, R., Scoon, K. and Levine, P.H. (1974) Hydrogen peroxide and platelet function. Blood, 43, 645-656.

[48] Levine, P.H., Weinger, R.S., Simon, J., Scoon, K.L and Krinsky, N.I. (1976) Leucocyte-platelet interaction. Re- lease of hydrogen peroxide by granulocytes as a modulator of platelet reactions. Journal of Clinic Investigation, 57, 955-963. doi:10.1172/JCI108372

[49] Stuart, M.J. and Holmsen, H. (1977) Hydrogen peroxide, an inhibitor of platelet function: effect on adenine nucleotide metabolism, and the release reaction. American Journal of Hematol, 2, 53-63.

[50] Machovich, R. and Owen, W.G. (1990) The elastase-mediated pathway of fibrinolysis. Blood Coagulation \& Fibrinolysis, 1, 79-90. doi:10.1097/00001721-199003000-00011

[51] Born, G.V.R., Bergquist, D. and Arfors, K.E. (1976) Evidence for inhibition of platelet activation in blood by a drug effect on erythrocytes. Nature, 259, 233-235. doi: $10.1038 / 259233 \mathrm{a} 0$

[52] Bergquist, D. and Arfors, K.E. (1980) Haemostatic platelet plug formation in the isolated rabbit mesenteric preparation-An analysis of red blood cell participation. Thrombosis and Haemostasis, 44, 6-8.

[53] Schmid-Schdnbein, H., et al. (1979) Basic aspects of blood trauma. Schattauer Verlag, Stuttgart, 322-340.

[54] Tiefenbach, H. J., Durchschlag, H., Schneider, G. and Jaenicke, R. (2004) Thermodynamic analysis of serum albumin denaturation by sodium dodecyl sulfate. Aqueous polymer dispersions, 124, 130-140.

[55] Schmid-Schdnbein, H., Born, G.V.R., Richardson, P.D., Cusack, N., Rieger, H., Forst, R., Rohling-Winkel, J., Blasberg, P. and Wehmeyer, A. (1981) Rheology of thrombotic processes in flow: The interaction of erythrocytes and thrombocytes subjected to high flow forces. Biorheology, 18, 415-444.

[56] Meireles, M., Aimar, P. and Sanchez, V. (2004) Albumin denaturation during ultrafiltration: Effects of operating conditions and consequences on membrane fouling. Biotechnology and Bioengineering, 38, 528-534. doi:10.1002/bit.260380511

[57] Ricciardi, M.J., Knight, B.P., Martinez, F.J. and Rubenfire, M. (1998) Inhaled nitric oxide in primary hypertension: A safe and effective agent for predicting response to nifedipine. Journal of the American College of Cardiology, 32, 1068-1073. doi:10.1016/S0735-1097(98)00361-1

[58] Mathisen, D.J., Kuo, E.Y., Hahn, C., et al. (1998) Inhaled nitric oxide for adult respiratory distress syndrome after pulmonary resection. The Annals of Thoracic Surgery, 66, 1894-1902. doi:10.1016/S0003-4975(98)01167-9

[59] Weber, A., Strobach, H. and Schror, K. (1993) Direct inhibition of platelet function by organic nitrates via nitric oxide formation. European Journal of Pharmacology, 247, 29-37. doi:10.1016/0922-4106(93)90134-U

[60] Moro, M.A., Russell, R.J., Cellek, S., et al. (1996) GMP mediates the vascular and platelet actions of nitric oxide: Confirmation using an inhibitor of the soluble guanylyl cyclase. Proceedings of the National Academy of Sciences, 93, 1480-1485. doi:10.1073/pnas.93.4.1480

[61] Aoki, H., Inoue, M., Mizobe, T., et al. (1997) Platelet function is inhibited by nitric oxide liberation during nitroglycerin-induced anaesthesia. British Journal of Anaesthesia, 79, 476-481. doi:10.1093/bja/79.4.476 
[62] Nong, Z., Hoylaerts, M., Van, Pelt N., et al. (1997) Nitric oxide inhalation inhibits platelet aggregation and platelet-mediated pulmonary thrombosis in rats. Circulation Research, 81, 865-869. doi:10.1161/01.RES.81.5.865

[63] Brune, B. and Hanstein, K. (1998) Rapid reversibility of nitric oxide induced platelet inhibition. Thrombosis Research, 90, 83-91. doi:10.1016/S0049-3848(98)00024-3

[64] Gries, A., Bode, C., Peter, K., et al. (1998) Inhaled nitric oxide inhibits human platelet aggregation, p-selectin expression, and fibrinogen binding in vitro and in vivo. Circulation, 97, 1481-1487. doi:10.1161/01.CIR.97.15.1481

[65] Kuo, S., Chen, C.Y., Lin, C.S. and Chiang, S.H. (2010) Wound bleeding control by low temperature air plasma. IEEE Transactions on Plasma Science, 38, 1908-1914. doi:10.1109/TPS.2010.2047028

[66] Kuo, S.P., Chen, C.Y., Lin, C.S. and Chiang, S.H. (2012) Applications of air plasma for wound bleeding control and healing. IEEE Transactions on Plasma Science, 40, 1117-1123. doi:10.1109/TPS.2012.2184142

[67] Finazzi-Agro', A., Menichelli, A., Persiani, M., Biancini, G. and Del Principe, D. (1982) Hydrogen peroxide release from human blood platelets. Biochimica et Biophysica Acta, 718, 21-25. doi:10.1016/0304-4165(82)90004-6

[68] Del Principe, D., Menichelli, A., De Matteis, W., Di Giulio, S., Giordani, M., Savini, I. and Finazzi-Agro', A. (1991) Hydrogen peroxide is an intermediate in the platelet activation cascade triggered by collagen, but not by thrombin. Thrombosis Research, 62, 365-375. doi:10.1016/0049-3848(91)90010-T

[69] Del Principe, D., Menichelli, A., De Matteis, W., Di Corpo, M.L., Di Giulio, S. and Finazzi-Agro', A. (1985) Hydrogen peroxide has a role in the aggregation of human platelets. FEBS Letters, 185, 142-146. doi:10.1016/0014-5793(85)80758-4
[70] Pratico, D., Iuliano, L., Alessandri, C., Camastra, C. and Violi, F. (1993) Polymorphonuclear leukocyte-derived $\mathrm{O}_{2^{-}}$ reactive species activate primed platelets in human whole blood. American Journal of Physiology, 264, H1582-H1587.

[71] Madison, K.C. (2003) Barrier function of the skin: "La raison d'être" of the epidermis. Journal of Investigative Dermatology, 121, 231-241. doi:10.1046/j.1523-1747.2003.12359.x

[72] Nguyen, D.T. Orgill, D.P. and Murphy, G.F. (2009) Biomaterials for treating skin loss. CRC Press, Boca Ratons.

[73] Clark, R.A.F. (1996) Wound repair: Overview and general considerations. In: The molecular and cellular boilogy of wound repair. Plenum Press, New York, 3-50.

[74] Levenson, S.M., Geever, E.F., Crowley, L.V., Oates, J.F., Berard, C.W. and Rosen, H. (1965) The healing of rat skin wounds. Annals of Surgery, 161, 293-308.

[75] Harman, D. (1965) Aging: A theory based on free radical and radiation chemistry. Journal of Gerontology, 11, 298300.

[76] Rodriguez, P.G., Felix, F.N., Woodley, D.T. and Shim, E.K. (2008) The role of oxygen in wound healing: A review of the literature. Dermatological Surgery, 34, 1159. 1169.

[77] Tandara, A.A. and Mustoe, T.A. (2004) Oxygen in wound healing-More than a nutrient. World Journal of Surgery, 28, 294-300.

[78] Whitney, J.D. (1989) Physiological effects of tissue oxygenation on wound healing. Heart Lung, 18, 466-474.

[79] Davis, J.C. and Hunt, T.K. (1988) Problem wounds: The role of oxygen. Elsevier, Berlin.

[80] La Van, F.B. and Hunt, T.K. (1990) Oxygen and wound healing. Clinics in Plastic Surgery, 17, 463-472. 